\title{
Confrontando a visão clássica da ação empreendedora: a lógica effectuation como forma de lidar com incertezas
}

\author{
Confronting the classical view of entrepreneurial action: the \\ effectuation logic as a way to cope with uncertainty
}

Bruno Rossener Barros ${ }^{1}$

Tiago Fonseca Albuquerque Cavalcanti Sigahi

Patrícia Saltorato ${ }^{3}$

${ }^{1}$ Universidade Federal de São Carlos - campus Sorocaba Consultor de Inovação na LAJE. Rio de Janeiro/RJ, Brasil brunorossener@gmail.com

${ }^{2}$ Universidade de São Paulo - Escola Politécnica Doutorando em Engenharia de Produção. São Paulo/SP, Brasil tiagosigahi@usp.br

${ }^{3}$ Universidade Federal de São Carlos - campus Sorocaba Doutora em Engenharia de Produção Professora Adjunta do Departamento de Engenharia de Produção. Sorocaba/SP, Brasil patriciasaltorato@gmail.com

\begin{abstract}
Resumo
O effectuation é uma das teorias mais citadas na literatura de empreendedorismo. Contudo, diversos autores têm apontado a necessidade de realização de estudos empíricos que validem tal abordagem. Visando atender essa lacuna, analisou-se a ação empreendedora nos processos de identificação, avaliação e exploração da oportunidade de negócio de uma startup com base nos conceitos do effectuation. O método utilizado foi o estudo de caso, apoiado por entrevistas, observação direta e análise documental. Constatou-se o alinhamento entre a ação empreendedora dos fundadores da empresa e os pilares do effectuation (perdas toleráveis, alianças estratégicas, exploração das contingências e controle de um futuro imprevisível). Esse trabalho possui implicações para a literatura, ao fornecer um caso empírico que contribui para a validação do effectuation; e implicações práticas, ao possibilitar aos atores do ecossistema de inovação um maior entendimento sobre as ações dos empreendedores para lidar com incertezas.
\end{abstract}

Palavras-chave: Effectuation. Causation. Empreendedorismo. Ação empreendedora. Incerteza.

\begin{abstract}
Effectuation is one of the most cited theories on entrepreneurship research. However, several authors have called for empirical studies in order to validate this approach. Aiming to address this gap, this study analyzed the entrepreneurial action in the processes of identification, evaluation and exploration of the business opportunity of a startup based on the concepts of effectuation. A case study was conducted using interviews, direct observation and document analysis. We found strong evidence of the alignment between the founder's entrepreneurial action and the pillars of effectuation (affordable loss, strategic alliances, exploitation of contingencies, and control of an unpredictable future). As implications for the literature, this article adds to the research on effectuation by providing an empirical case that contributes to the validation of this approach. As a practical implication, it allows the actors of the innovation ecosystem to better understand the entrepreneurs' actions in coping with uncertainties.
\end{abstract}

Keywords: Effectuation. Causation. Entrepreneurship. Entrepreneurial action. Uncertainty. 
1 Introdução

O empreendedorismo como campo de pesquisa é relativamente novo. Conforme Shane e Venkataraman (2000), os pesquisadores dessa área estão interessados no estudo dos processos de identificação, avaliação e exploração de oportunidades de negócios.

Frequentemente, a ação empreendedora resulta em importantes inovações (Bird, Schjoedt, \& Baum, 2012) que, por sua vez, são a força motriz do desenvolvimento econômico (Schumpeter, 2004). Questões como a melhoria dos serviços de saúde, o desenvolvimento de energias alternativas e a revitalização das cidades, são processos de inovação (Dougherty, 2017). Nesse cenário, diversos autores têm identificado uma capacidade reduzida de grandes empresas em lidar com incertezas (Leifer et al., 2000; De Meyer, Loch, \& Pich, 2002; Rice, O’Connor, \& Pierantozzi, 2008), tornando a figura do empreendedor cada vez mais necessária à criação de novas soluções e negócios.

Até o início dos anos 2000, era dominante a visão causal (causation) sobre ação empreendedora (Shane, 2012), típica de livros-texto clássicos de autores como Philip Kotler e Michael Porter, que retratam o processo de maneira normativa e prescritiva, onde a ação empreendedora depende de um fim dado. Nos casos em que o empreendedor possui clareza à priori sobre o tipo de empresa que quer criar e em qual mercado deseja atuar, técnicas como pesquisa de mercado são válidas como estratégias para penetrá-lo (Sarasvathy, 2001). Segundo Tasic (2007), na visão clássica processual, o empreendedor deve, para abrir seu negócio, definir uma segmentação de mercados-alvo, estabelecer um plano de marketing e posicionar seus produtos e serviços no mercado. Tratase da abordagem STP (do inglês, Segmentation-Targeting-Positioning) sugerida por Kotler (1991), que é, desde os anos 1960, a forma dominante de análise de novos negócios (Tasic \& Andreassi, 2008).

Em colisão com tal lógica, o trabalho seminal de Sarasvathy (2001) representa um marco no estudo do tema. A importância e o impacto do trabalho de Sarasvathy estão na crítica explícita à visão clássica. Com base em autores icônicos da literatura de gestão como James G. March, Henry Mintzberg e Karl E. Weick, a autora desenvolve o conceito de effectuation, que viria a mudar a maneira de se pensar sobre a ação empreendedora: incorpora-se a incerteza à análise do processo empreendedor, que nem sempre ocorre de forma ordenada e estratégica (Shane, 2012).

O effectuation é uma das teorias emergentes mais citadas na literatura de empreendedorismo (Fisher, 2012; Perry, Chandler, \& Markova, 2012). Contudo, o conhecimento sobre effectuation encontra-se ainda na transição para um estágio de desenvolvimento maduro e, portanto, os pesquisadores da área têm apontado a necessidade de realizar mais estudos empíricos que validem tal abordagem (Sarasvathy, 2001; Tasic, 2007; Matalamäki, 2017).

Esse artigo pretende contribuir para preencher essa lacuna. O objetivo do estudo é aplicar os conceitos do effectuation na análise dos processos de identificação, avaliação e exploração de uma oportunidade de negócio em ambiente de incerteza. Para tanto, investigou-se o caso de uma startup pioneira no uso de inteligência artificial e matching cultural no processo de recrutamento e seleção para empresas (doravante IA-Recruta), que atua em um ambiente de alta incerteza. Foi possível identificar diversos componentes da lógica effectuation no caso estudado que contribuem para a validação dessa abordagem. 
Esse artigo está organizado da seguinte maneira: na seção 2, discute-se as abordagens causation e effectuation, destacando-se os conceitos-chave que as contrapõem. Em seguida, na seção 3, apresenta-se a metodologia, detalhando-se as etapas e procedimentos para a realização do estudo de caso. A seção 4 discute o caso da IA-Recruta à luz da abordagem effectuation. Por fim, a seção 5 inclui uma síntese das contribuições, as limitações do estudo e sugestões de trabalhos futuros.

\section{Fundamentação teórica: do causation ao effectuation}

De acordo com Sarasvathy (2003), diversos estudos tentaram relacionar traços psicológicos de empreendedores com o sucesso de suas empresas, sem, contudo, chegar a conclusões sólidas. Logo, o empreendedorismo começou a ser estudado não mais como características de alguns indivíduos dotados de certo tipo de personalidade, mas sob uma perspectiva processual. Assim, pesquisadores começaram a buscar formas de explicar a ação empreendedora como um processo estruturado de análise, previsão e planejamento (Shane \& Venkataraman, 2000; Neck \& Greene, 2011). A abordagem clássica, como é conhecida, está ancorada nos trabalhos de gurus do management como Ansoff, Porter e Kotler, e segue os preceitos do causation. A ideia de linearidade fica clara na forma como Kotler (1991) denominou sua abordagem: Segmentation-TargetingPositioning.

Sarasvathy (2001) critica de forma contundente as características prescritivas e normativas dessa abordagem, que pressupõe o conhecido ou o dado. A autora confronta a visão clássica colocando questões como: Como tomar decisões de precificação quando a empresa ainda não existe (i.e., não há conhecimento sobre receita e/ou custos), ou ainda em situação mais interessante, quando o mercado para o produto/serviço ainda não existe (i.e., não há conhecimento sobre demanda)? Como contratar alguém para uma organização que ainda não existe? Como definir um valor para uma empresa em um setor que não existia há cinco anos e que mal está consolidado no presente? Partindo dessas questões, a autora apresenta argumentos consistentes para demonstrar sua tese de que as abordagens dominantes até então, baseadas no causation e caracterizadas como normativas, prescritivas e lineares, não eram adequadas à análise de situações que envolvem a incerteza e o desconhecido (Sarasvathy, 2001, 2003, 2008; Shane, 2012).

Sarasvathy (2001) explica que a característica distintiva entre causation e effectuation (Figura 1) é o conjunto de escolhas: escolher entre meios para criar um efeito particular ou escolher entre muitos efeitos possíveis usando um conjunto particular de meios - o que implica em diversas outras diferenças. 
Figura 1 - Característica distintiva entre causation e effectuation

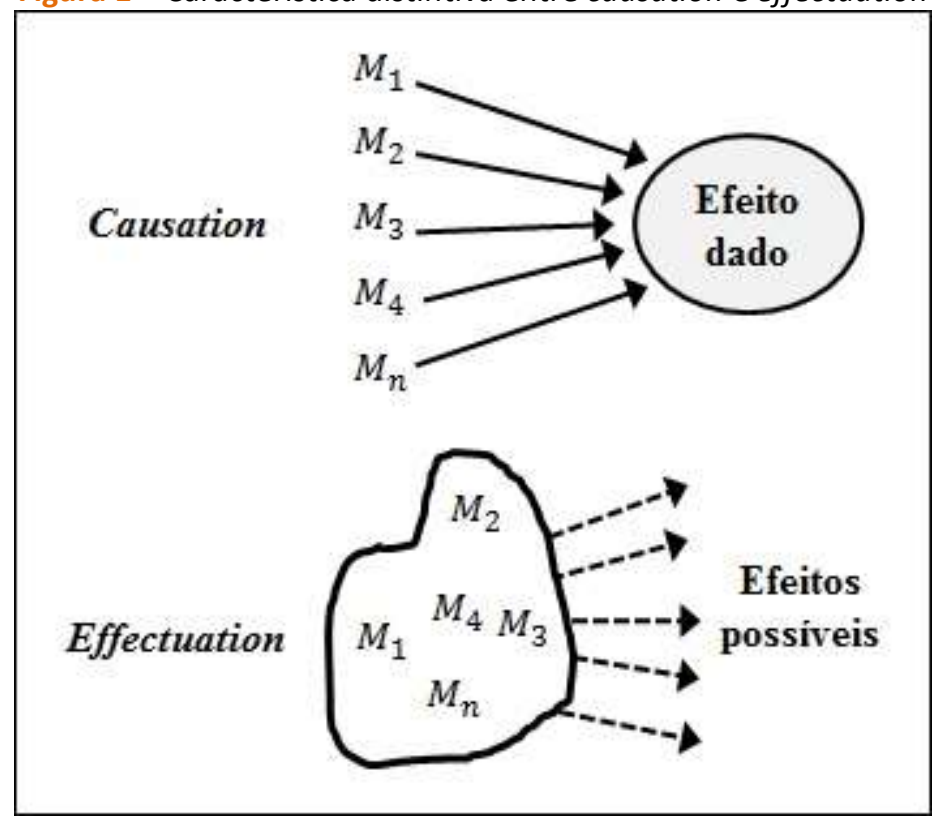

Fonte: Adaptado de Dew e Sarasvahty (2002).

Para Sarasvathy (2008), a lógica causal e a lógica effectual são duas abordagens alternativas e não excludentes utilizadas por empreendedores no processo de criação e desenvolvimento de novos negócios; porém, há entre elas distinções conceituais determinantes, como mostra a Tabela 1:

Tabela 1 - Diferenças conceituais entre causation e effectuation

\begin{tabular}{lll}
\multicolumn{1}{c}{ Parâmetro } & \multicolumn{1}{c}{ Causation } & \multicolumn{1}{c}{ Effectuation } \\
\hline Conceitos econômicos & Economia clássica (Kirzner, 1979) & Comportamental (Simon, 1959) \\
Estratégia & Deliberada (Ansoff, 1965) & Emergente (Mintzberg, 1978) \\
Criação de oportunidades & Sistemática (Fiet \& Patel, 2006) & Ação humana (Weick, 1979) \\
$\begin{array}{l}\text { Desenvolvimento de } \\
\text { oportunidades }\end{array}$ & Função do retorno sobre investimentos & Função de acontecimentos \\
\hline
\end{tabular}
Fonte: Elaborado a partir de Sarasvathy $(2001,2003,2008)$ e Salusse e Andreassi (2016).

Dew, Read, Sarasvathy e Wiltbank (2009) sugerem que os conceitos de effectuation e causation sejam discutidos com base em cinco pontos: visão de futuro, bases para a tomada de ação, pré-disposição ao risco, atitude perante terceiros e atitude perante contingências inesperadas.

Causation e effectuation possuem visão de futuro preditiva e criativa, respectivamente. O primeiro enxerga o futuro como uma continuação do passado e, por isso, uma previsão acurada é necessária e útil. Já o segundo assume que o futuro é moldado - pelo menos parcialmente - pelas partes interessadas, o que faz com que a predição não seja nem fácil nem útil. No processo causation, as decisões são tomadas com base em objetivos pré-definidos, enquanto no effectuation tais objetivos emergem a partir dos caminhos de ação imaginados com base nos meios existentes. Quanto à pré-disposição ao risco, a diferença entre os processos pode ser explicada pelo primeiro princípio apontado por Sarasvathy (2001): o causation busca maximizar o retorno esperado, focando no ganho potencial de determinada decisão, enquanto o effectuation busca oportunidades adequadas e 
satisfatórias visando limitar a potencial perda. A atitude perante terceiros é explicada pelo segundo princípio de Sarasvathy (2001): no causation as relações são conduzidas com base em análise competitiva e no effectuation os relacionamentos são tratados como parcerias e alianças estratégicas que moldam a forma e a trajetória do negócio. Por fim, quanto à atitude perante contingências inesperadas, o causation tenta evitá-las por meio de predições acuradas, pois as entendem como obstáculos. De outro modo, o effectuation as trata como oportunidades e, se preciso, transforma continuamente seus objetivos.

Sarasvathy (2003) argumenta que o effectuation tende a ocorrer quando novos produtos se encontram com novos mercados, espaço conhecido como "quadrante suicida" (Figura 2):

\begin{tabular}{|c|c|c|c|}
\hline & & \multicolumn{2}{|c|}{ Mercado } \\
\hline & & Existente & Novo \\
\hline \multirow{2}{*}{$\begin{array}{l}\text { 윽 } \\
\text { 믕 } \\
\text { 은 }\end{array}$} & Existente & & \\
\hline & Novo & & $\begin{array}{l}\text { Quadrante } \\
\text { suicida }\end{array}$ \\
\hline
\end{tabular}

Fonte: Adaptado de Sarasvathy (2003).

Profissionais experientes de marketing têm como objetivo evitar rotineiramente esse espaço. Em contrapartida, empreendedores experientes sabem que é justamente (não somente) no quadrante suicida que emergiram grandes empresas, como por exemplo, a General Electric e a Apple (Sarasvathy, 2003).

Grande parte das empresas estabelecidas atuam nos demais quadrantes, isto é, onde se assume que o mercado, o produto ou ambos existem - razão pela qual não se aplica a lógica effectuation. Por outro lado, empresas nascentes lidam exatamente com as inquietações com base nas quais Sarasvathy (2001) justifica a necessidade de uma nova teoria, como por exemplo: como tomar decisões sobre preço se a empresa ainda não existe ou se nem mesmo o mercado existe? Como contratar pessoal para uma empresa que ainda não existe ou até mesmo como convencê-las a pleitear uma vaga?

Como aponta Sarasvathy (2001), os effectuators se apoiam em três categorias de “meios": quem eles são, o que eles sabem e quem eles conhecem. Em empresas nascentes, o empreendedor faz uso desses meios para mudar seus objetivos e até mesmo construí-los ao longo do tempo. Assim, tais fatores são determinantes em empresas nascentes, pois influenciam diretamente cada decisão tomada e, portanto, o caminho de toda a empresa. Em empresas estabelecidas, não há essa autonomia, estando a decisão sujeita à aprovação de diversas instâncias para ocorrer. A importância desses fatores é "dissolvida", de modo que maximizar o potencial ganho é mais importante do que quem é, o que sabe e quem conhece o tomador de decisão.

O processo de effectuation é dinâmico e iterativo, conforme mostra a Figura 3: 
Figura 3 - Modelo dinâmico e iterativo do processo effectuation

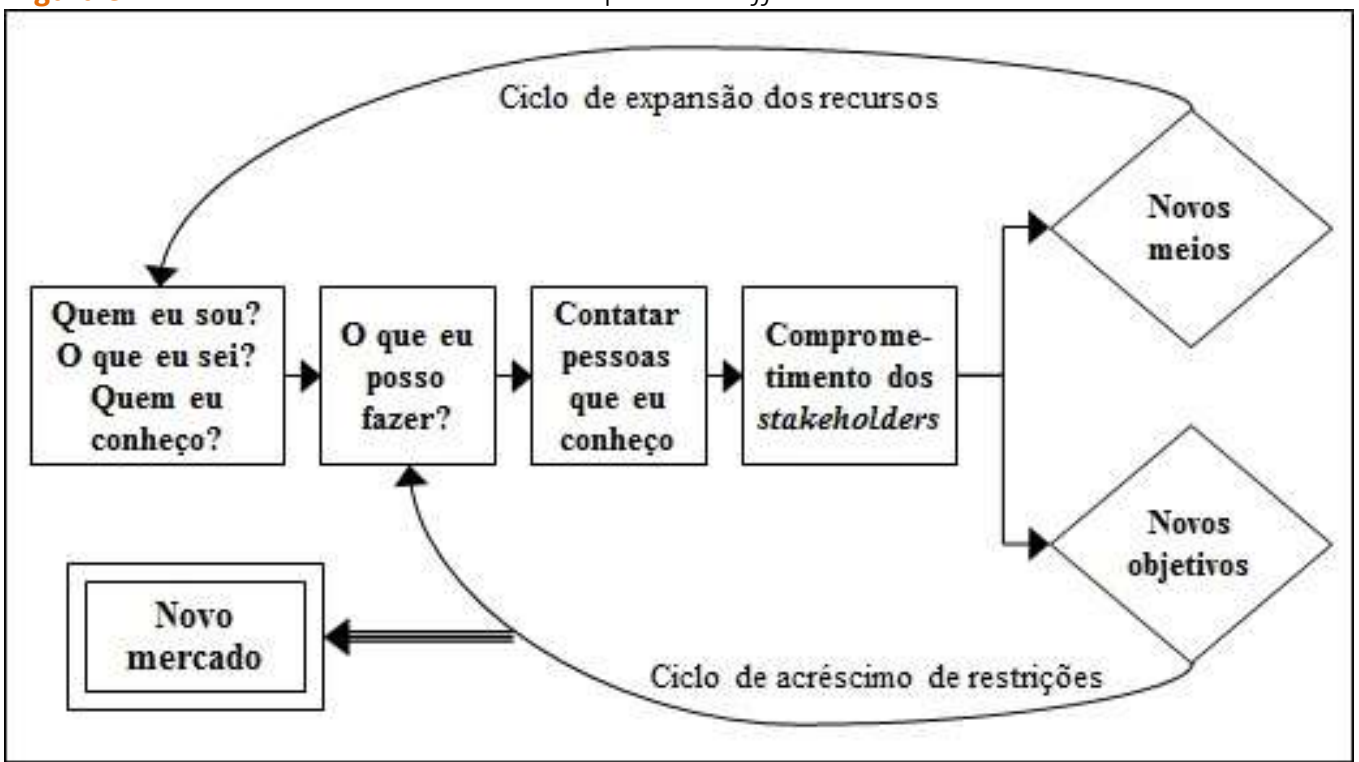

Fonte: Adaptado de Sarasvathy e Dew (2005) e Wiltbank, Dew, Read e Sarasvathy (2006).

O raciocínio por trás da lógica effectuation é: "ao passo que se pode controlar o futuro, não se faz necessário prevê-lo" (Sarasvathy, 2003). A premissa é a de que grande parte do futuro é parte de decisões humanas e, assim, o empreendedor pode trazer à mesa parceiros que the proporcionem as condições para construí-lo, não se fazendo necessário despender tempo, esforço e outros recursos tentando prevê-lo.

Conforme Wiltbank, Dew, Read e Sarasvathy (2006), para construir o futuro, que é incerto e imprevisível, o empreendedor que usa a lógica effectuation parte dos recursos que já possui em busca de pessoas que possam Ihe fornecer inputs (e.g., conhecimento, competência específica, investimento, espaço físico) para que ele possa proceder. Tais pessoas podem envolver tanto amigos e família quanto pessoas fora do seu círculo social, mas que possuem interesse em sua ideia. Ao se comprometerem com o desenvolvimento do empreendimento, estes novos atores contribuem para viabilizar sua execução.

O processo effectual procede para além de ações individuais e tarefas, pois se interessa pelos resultados e objetivos que emergem a partir das relações externas, que se tornam evidentes apenas com o desdobramento de decisões, ações e eventos ao longo do tempo. Dessa forma, segundo Sarasvathy e Kotha (2001), enquanto o processo causal parte de um mercado pré-determinado e nele define como alvo um ou dois segmentos, o effectuation parte de um cliente único ou parceiro estratégico (descoberto através de seus recursos pré-existentes ou até acidentalmente) para então criar novos segmentos ou mercados que não existiam no começo do processo.

Com base no exposto, a análise do caso da IA-Recruta se dá a partir dos quatro princípios do effectuation propostos por Sarasvathy (2001):

i) Perdas toleráveis versus retornos esperados: ao invés de buscar a maximização do retorno potencial do negócio, determina-se o nível tolerável de perdas que poderão ocorrer durante as fases de experimentação; 
ii) Alianças estratégicas versus análise competitiva: diferentemente das propostas prescritivasnormativas como as de Porter (1979) e Kotler (1991), o effectuation foca em parcerias estratégicas e no comprometimento das partes interessadas como forma de redução de incertezas;

iii) Exploração das contingências versus exploração de conhecimento pré-existente: processos causais focam em conhecimento(s) pré-existente(s) (e.g., expertise em uma nova tecnologia em particular), e o exploram como fonte de vantagem competitiva. O effectuation propõe que o empreendedor enxergue as contingências como oportunidades.

iv) Controle de um futuro imprevisível versus previsão de um futuro incerto: o causation foca em aspectos previsíveis de um futuro incerto, enquanto o effectuation volta sua atenção aos aspectos controláveis de um futuro inerentemente imprevisível.

\section{Metodologia}

Segundo Edmondson e Mcmanus (2007), abordagens qualitativas de investigação são mais apropriadas para o estudo de novos construtos por permitir emergir temas promissores conforme a entrada de novos dados. Nesse sentido, justifica-se a escolha da abordagem qualitativa para estudar o processo effectuation por tratar-se de uma teoria relativamente nova em um estágio de amadurecimento (Matalamäki, 2017).

Quanto ao método, considerando a necessidade de estudos empíricos sobre o tema (Sarasvathy, 2001; Tasic, 2007; Matalamäki, 2017), optou-se pelo estudo de caso devido à aderência ao problema em questão, conforme mostra a Tabela 2:

Tabela 2 - Adequação do método do estudo de caso ao problema de pesquisa

\begin{tabular}{cc}
\hline $\begin{array}{c}\text { Características de um problema adequado à } \\
\text { utilização do estudo de caso }\end{array}$ & Características do problema de pesquisa \\
\hline Fenômeno contemporâneo & $\begin{array}{c}\text { Utilização da lógica effectuation na criação e desenvolvimento de } \\
\text { novos negócios }\end{array}$ \\
$\begin{array}{c}\text { Aprofundamento do conhecimento } \\
\text { sobre problema }\end{array}$ & $\begin{array}{c}\text { Deja-se discutir e analisar um caso de validação da abordagem } \\
\text { effectuation }\end{array}$ \\
Contexto de vida real & $\begin{array}{l}\text { Processo de criação de uma start up pioneira no uso de } \\
\text { inteligência artificial e matching cultural no processo de } \\
\text { recrutamento e seleção para empresas }\end{array}$
\end{tabular}
Fonte: Elaborado pelos autores com base em Yin (2015).

A escolha da empresa estudada se deu de forma deliberada por tratar-se de uma startup de tecnologia que atua em um mercado nascente e que oferece um produto inovador. Em outras palavras, é uma empresa que se encontra no quadrante suicida, conforme proposto por Sarasvathy (2003), situação em que se aplica a lógica effectuation.

Conforme mostrado na Tabela 3, foram utilizados três instrumentos para a coleta de dados: entrevistas, realizadas com os fundadores da empresa; observação direta; e análise de documentos da empresa. 
Tabela 3 - Instrumentos, períodos e fontes de coleta de dados

\begin{tabular}{|c|c|c|}
\hline Instrumento & Período de coleta & Fontes de dados \\
\hline \multirow[t]{3}{*}{ Entrevista } & 10/2016 а 01/2017 & $\begin{array}{l}\text { Proprietário } 1 \text { (P1): fundador e atual responsável pelas áreas de } \\
\text { inteligência de dados, comercial e financeira }\end{array}$ \\
\hline & & $\begin{array}{l}\text { Proprietário } 2 \text { (P2): sócia e atual responsável pela metodologia de } \\
\text { mapeamento cultural }\end{array}$ \\
\hline & & $\begin{array}{l}\text { Proprietário } 3 \text { (P3): sócio e responsável pelo desenvolvimento do } \\
\text { produto e por atividades de comunicação e marketing digital }\end{array}$ \\
\hline $\begin{array}{l}\text { Observação } \\
\text { direta }\end{array}$ & 01/2016 а 01/2017 & $\begin{array}{l}\text { Escritório da empresa, reuniões internas, reuniões com parceiros, } \\
\text { situações de venda }\end{array}$ \\
\hline $\begin{array}{l}\text { Análise } \\
\text { documental }\end{array}$ & 01/2016 a 01/2017 & $\begin{array}{l}\text { Atas de reuniões internas, anotações de reuniões com stakeholders, } \\
\text { relatórios de serviços prestados, planos de ação, manuais da } \\
\text { empresa }\end{array}$ \\
\hline
\end{tabular}

Fonte: Elaborado pelos autores.

O roteiro da entrevista (Tabela 4) foi desenvolvido com base na proposta de Tasic (2007) e Tasic e Andreassi (2008) devido à semelhança dos objetivos de pesquisa e pela importância da colaboração do pesquisador Robert Wiltbank, ativo colaborador de Saras Sarasvathy, para sua construção. Segundo Tasic (2007), o roteiro de entrevista desenvolvido visa compreender em que extensão empreendedores constroem empresas usando effectuation.

Tabela 4 - Roteiro de entrevista

\begin{tabular}{lll}
\hline$\#$ & \multicolumn{1}{c}{ Questão } & \multicolumn{1}{c}{ Indicadores da lógica effectuation } \\
\hline 1 & Como a empresa foi formada? Quais foram seus objetivos, & Questão 1: Objetivos vagos no início e \\
& eles eram específicos/claros ou amplos? & influência dos fundadores (quem eu \\
& & conheço, o que eu sei, e quem sou)
\end{tabular}

2 Como vocês selecionaram seus objetivos, mercados-alvo, Questões 2, 3, 4 e 5: Realização de muito produtos, serviços? O que era atraente em relação a cada um poucas (ou nenhuma) pesquisas de e de onde tiraram a ideia? Que tipo de pesquisa de mercado mercado e/ou predições a respeito do valor foi feita (se é que foi feita)? potencial das escolhas alternativas disponíveis; a atratividade dos objetivos

3 Em que medida vocês concentram seus investimentos e o (efeitos) estão na factibilidade e não posicionamento da empresa para o sucesso em função das somente na maximização dos lucros; as predições de mercado? ideias surgem largamente por meio de

4 Quando novos meios/recursos foram apresentados, vocês estavam dispostos a reconsiderar seus objetivos? experiências pessoais, ao invés de esforços deliberados de busca.

5 Vocês procuraram meios e recursos para validar seus objetivos pré-existentes?

6 Vocês trabalham com algum parceiro? Como estes relacionamentos iniciaram e por quê? Vocês procuram outros parceiros ao mesmo tempo?

Questões 6, 7, 8 e 9: O effectuation sugere que pré-comprometimentos / acordos com parceiros desempenham um papel vital no desenvolvimento dos objetivos, 
7 Que tipo de parceiros foram escolhidos? Algum deles era um potencial concorrente? Trabalhou-se com os parceiros de modo a promover/aperfeiçoar alguma mudança substancial no modelo de negócio? Ou os parceiros focaram na execução de objetivos pré-existentes?

8 Vocês trabalham de forma mais cooperativa ou competitiva?

9 Como vocês escolheram os locais de estabelecimento do negócio?

10 Que surpresas surgiram ao longo de seus caminhos? Como lidaram com essas surpresas?

$11 \mathrm{O}$ que aconteceu quando um cliente veio até vocês e queria algo que não ofereciam à época? especialmente no início; ao invés de buscar pelo "melhor" parceiro, eles trabalhariam com parceiros que estivessem comprometidos com o processo

12 Em que vocês estão trabalhando agora ou trabalharão em seguida, no futuro? Por que escolheram estas coisas?

13 Quando fazem decisões de investimento, como decidem quanto irão investir?

Questões 10 e 11: O effectuation sugere que os empreendedores se alavancam com contingências, transformando-as em novas oportunidades, ao invés de absorvê-las e evitá-las porque elas poderiam tirá-los dos esforços de construção do novo negócio

Questões 12 e 13: Ao longo do tempo, os próximos passos podem ser selecionados de uma forma mais causal. É possível rastrear o desenvolvimento destes processos causais ou eles ainda estão trabalhando de forma effectual?

Fonte: Elaborado com base em Tasic (2007) e Tasic e Andreassi (2008).

As entrevistas foram realizadas presencialmente, no escritório da empresa, e duraram cerca de 20 minutos. Obteve-se o consentimento dos entrevistados para que a entrevista fosse gravada. As respostas foram transcritas e os principais pontos foram organizados de forma temporal de forma a possibilitar a recriação da história da IA-Recruta por meio da técnica de estratégia narrativa, como recomendado por Langley (1999). Esta técnica, segundo o autor, consiste na construção de uma história detalhada a partir dos dados puros. Posteriormente, juntamente com os dados obtidos a partir da observação direta e análise documental, foi realizada uma análise mais sistematizada do caso, que se deu sob a perspectiva dos quatro princípios do effectuation (Sarasvathy, 2001) apresentados anteriormente.

\section{Estudo de caso}

\subsection{Caracterização da empresa: IA-Recruta}

A IA-Recruta teve início em 2014 quando sua fundadora (P1), inspirada pelo site de namoro online eHarmony, resolveu criar sua própria startup aplicando um modelo semelhante, porém, aplicado ao processo de seleção de empresas.

A IA-Recruta desenvolveu, ao longo de 2015, um software de mapeamento de cultura organizacional e análise de fit cultural. Por meio de questionários, empresas mapeiam a sua cultura organizacional e entendem as preferências de trabalho dos seus candidatos, de forma a avaliar a sua compatibilidade com a empresa. 
O diferencial da ferramenta e o que a torna uma solução inovadora é a abordagem de matching cultural focada em cultura organizacional com uso de tecnologia, no caso, de inteligência artificial. A solução funciona através do cruzamento das respostas e questionários de mapeamento cultural, tanto por parte da empresa quanto dos candidatos que nela querem trabalhar. O resultado dessa análise, que se dá através de redes neurais, é uma nota de fit cultural entre o candidato e a empresa, que é utilizada como critério de seleção no processo seletivo da empresa cliente. Atualmente, a empresa já atuou em processos de seleção de mais de 15 grandes empresas.

O mercado em que a empresa atua também pode ser considerado novo, pois, embora processos seletivos em empresas já existam há muito tempo, o uso de tecnologia nunca foi uma prioridade nesse mercado. Com o desenvolvimento de tecnologias cada vez mais inteligentes, porém, os empreendedores vislumbraram, entre os objetivos possíveis, a criação desse novo segmento no setor de recrutamento e seleção de profissionais.

A IA-Recruta conta com três sócios-fundadores, que possuem formações e experiências profissionais diversificadas. P1 possui formação em Administração, tendo trabalhado por quatro anos na área de recursos humanos (RH), e é responsável pelas áreas de inteligência de dados, comercial e financeira. P2 possui formação em Engenharia, com experiência de dois anos e meio em empreendedorismo, sendo responsável pela metodologia de mapeamento cultural da IA-Recruta. P3 possui formação em Publicidade e tem experiência com aceleração de startups digitais e consultoria empresarial com foco em estratégia, fusões e aquisições, gestão de mudanças e RH; é responsável pelo desenvolvimento do produto e por atividades de comunicação e marketing digital.

\subsection{O processo de criação da IA-Recruta}

A IA-Recruta surgiu a partir de uma vontade pessoal de P1, fundador da empresa, em empreender na área de $\mathrm{RH}$, o que estava diretamente relacionado à sua história profissional, isto é, quem ele conhecia e o que ele sabia com base em sua experiência de quatro anos na área de recursos humanos. Contudo, P1 não tinha clareza sobre qual seria a contribuição do seu negócio para o mercado em que queria atuar.

Fiquei três meses sabendo que queria empreender, montar uma empresa na área de $\mathrm{RH}$, mas eu não sabia o que seria a solução, que problema a gente ia resolver.

Visando um maior entendimento sobre o que poderia ser transformado em negócio, P1 acionou sua rede de contatos, construída na época em que trabalhava na área.

Nesses três meses fiquei conversando com pequenas e grandes empresas, fiz mais de 50 conversas com empresas, tanto com gestores de $\mathrm{RH}$ quanto com gestores de outras áreas, para ouvir deles quais eram seus maiores problemas com relação a RH e o que eles achavam que poderia ser resolvido de forma diferente.

P1 não se limitou, porém, somente a empresas, mas quis entender também quais eram as principais queixas e dificuldades das pessoas com relação aos processos das áreas de RH nas empresas.

Fiz também a mesma coisa no lado das pessoas, buscando entender o que elas achavam do ambiente quando iam fazer uma entrevista, quando eram contratadas, 
do que elas sentiam falta e o que poderia ser feito diferente. Foram mais de 100 entrevistas com pessoas, focando numa idade de 23 a 35 anos.

Prosseguindo sua estratégia de conversar com o mercado, P1 procurou também empresas e especialistas que já prestavam serviço nessa área.

Feito isso, e com todas as documentações feitas, fui conversar com especialistas nessa área de $\mathrm{RH}$ : headhunters, empresas de programas de estágio e trainee, empresas de testes de perfil, etc.

A partir de todas essas conversas, foi possível mapear um problema que era frequentemente citado por todos no mercado.

Fiz isso até encontrar um problema que todos comentavam sobre: contrata-se pela competência técnica e demite-se pela comportamental.

Tendo identificado o problema, P1 passou a investigar fora da indústria de RH que tipo de soluções já existia para problemas semelhantes.

Encontrado esse problema, fui investigar fora da indústria de RH por soluções que pudessem ser aplicadas a esse problema. A solução que me pareceu mais próxima foi a da indústria de relacionamentos online, porque antes de saber no que empreender, eu tinha uma clareza muito grande que eu queria fazer um negócio que fosse escalável e usasse tecnologia.

P1, então, investigou como essas empresas funcionam a partir de conversas com seus fundadores.

Ele (o fundador da empresa) me aconselhou a estudar o caso do eHarmony, a principal plataforma nessa indústria, e me alertou que, por trás da plataforma deles, existe um lado estatístico muito forte para trazer essa escalabilidade.

Em seguida, P1 estudou profundamente o caso do eHarmony e foi atrás de pessoas especialistas em estatística.

Foi quando conheci uma pessoa que me apresentou alguém que pôde então me ajudar e me deixou claro de que era sim possível fazer o que eu queria, que era fazer esse matching entre candidatos e empresas. A forma que isso seria feito nem ele sabia ainda, mas precisaria ter os dados primeiro para entender que tipo de dados ele ia receber e como trabalhar com esses dados.

Tendo identificado o problema a ser resolvido (i.e., empresas contratam profissionais pelas competências técnicas e os demitem pelas competências comportamentais) e o conhecimento necessário para tal (i.e., estatística), P1 identificou ainda a necessidade de ampliar seus conhecimentos sobre cultura organizacional.

Quando comecei a ter essa clareza, foi a época que comecei a estudar mais sobre cultura organizacional para entender que tipo de pergunta iríamos fazer e que tipo de respostas iríamos obter. Aproveitei também o conhecimento que havia extraído das entrevistas com empresas e pessoas, para adicionar aos questionários perguntas sobre o que as empresas mais gostariam de saber sobre os candidatos e também o que os candidatos mais gostariam de saber sobre as empresas. 
Com apenas tais informações, e ainda sem investimento, a empresa começou a ser desenhada.

A partir daí que começou a ideia de a IA-Recruta ser uma solução e começamos a trabalhar no modelo, no método e na forma em que seriam feitos esses cruzamentos.

A partir desses estudos, a IA-Recruta criou um site onde era possível preencher um questionário para as pessoas descobrirem qual o seu "jeito de ser" no trabalho, a partir de quatro arquétipos: estruturado, desbravador, colaborativo ou superação. Paralelamente, buscou-se vender a ideia para empresas que quisessem usar a versão beta da ferramenta.

Pedimos para as empresas mais próximas da gente pedirem a seus colaboradores responderem nossos questionários para a gente identificar o 'jeito de ser' da empresa e rodamos também com as pessoas físicas para ver se elas respondiam o questionário.

A gente acredita muito na força dos relacionamentos. Eles abrem muitas portas. Todos os nossos (P1, P2, P3) relacionamentos facilitaram muito esse constante relacionamento com empresas, potenciais investidores, etc. Então, a gente busca muito usar a nossa própria rede de relacionamentos para conseguir algumas coisas para a IA-Recruta.

Antes de fazer algum planejamento sobre o futuro da IA-Recruta, os proprietários buscaram entender se o que estavam criando realmente resolvia realmente algum problema das empresas.

A gente antes validou que tinha gente que usava a nossa solução. A gente não gastou tempo montando um plano de negócios tradicional sem saber se essa solução resolveria realmente um problema das empresas.

No começo, a solução foi testada e validada principalmente por pequenas e médias empresas, que se tornaram parceiras. Atualmente, tanto características de produto quanto a estratégia do negócio já evoluíram a partir do feedback dos clientes.

Na nossa forma de empreender, a gente cria somente o mínimo que tem que ser criado para um produto conseguir mostrar o seu valor e testa. Se o resultado for bom, daí sim trabalhamos para criar algo melhor. Dessa forma, nosso ciclo de aprendizado é muito rápido e não podemos nos apegar à nossa primeira solução. Ela tem que estar em constante evolução.

No início de 2016, a IA-Recruta foi avaliada em R\$ 6 milhões e fez um levantamento de investimento-anjo de $\mathrm{R} \$ 600$ mil. A escolha dos investidores foi realizada de forma estratégica, pois os fundadores consideraram não apenas o montante de capital que estavam dispostos a investir, mas também o conhecimento, a experiência e os relacionamentos de cada um em áreas que a empresa considerava estratégicas para o negócio.

Com o investimento, a IA-Recruta contratou, no segundo trimestre de 2016, um cientista de dados para aperfeiçoar o sistema de matching entre candidatos e empresas e um desenvolvedor, que hoje ocupa o cargo de diretor de tecnologia, para melhorar o sistema web.

Antes do aumento do time, porém, a IA-Recruta começou a buscar por um local para ser o escritório da empresa. A solução veio através da própria família de P1. 
A localização do escritório veio pela facilidade de custo. Estamos dentro do escritório da minha família, então não temos que nos preocupar com custo de espaço e podemos gastar, assim, esse dinheiro para trazer gente para trabalhar. Além disso, o escritório também é bem localizado, então estamos perto dos nossos clientes.

No terceiro trimestre de 2016, depois de a empresa ter sido aprovada em um programa de aceleração que visa facilitar a entrada de soluções desenvolvidas por startups em grandes corporações, a IA-Recruta redefiniu seu público-alvo: as grandes empresas.

Estamos trabalhando hoje na construção de bons cases e na construção dessas métricas de sucesso junto a algumas grandes empresas.

A fundadora da empresa comentou também sobre como a IA-Recruta enxerga as mudanças e contingências nesse percurso.

As mudanças e surpresas no meio do caminho fazem parte do dia a dia do negócio. Com a velocidade hoje com que as coisas acontecem, todo mundo, independentemente do tamanho da empresa, tem que ser muito receptivo a mudanças e ser muito rápido para acompanhar essas mudanças. Mudanças são sempre muito bem vindas e o que vai fazer você não ficar pra trás vai ser o quão rápido você vai ser para acompanhar. O negócio é ser ágil para conseguir atender logo essas mudanças.

Para o futuro, a empresa vê como fundamental conseguir entregar bons resultados que resultem em cases para, como próximos passos, conseguir escalar a venda da solução.

Conseguindo construir bons cases e resolvendo o problema dos nossos clientes, nós vamos chamar a atenção de outros (clientes) e vamos aprender como vender. Isso nos possibilitará escalar a área comercial e, assim, poderemos atender mais clientes ao mesmo tempo e com a mesma solução.

\subsection{Análise do caso sob a perspectiva dos princípios do effectuation}

\subsubsection{Perdas toleráveis versus retornos esperados}

Segundo Sarasvathy (2001), enquanto o causation busca maximizar o retorno potencial de uma decisão selecionando estratégias ótimas, o effectuation pré-determina um nível tolerável de perda e foca na experimentação de diferentes estratégias possíveis dentro dos meios que estão disponíveis.

No caso estudado, fica evidente que no início do processo de criação da empresa não havia clareza em relação aos objetivos, isto é, o objetivo não era dado. Percebe-se a existência da hipótese de que o uso da tecnologia poderia ajudar de alguma forma a área de RH das empresas, mas não havia nenhum objetivo claro. Dessa forma, o enfoque da ação empreendedora não foi a maximização do retorno potencial do empreendimento, pois não se sabia à priori o tipo de empresa a ser construído, nem mesmo o segmento que iria atender.

Os fundadores iniciaram a criação da empresa com o mínimo de recursos possível: seu tempo, um computador, internet e sua rede de relacionamentos. Se por algum motivo não conseguisse dar continuidade à sua vontade de empreender, suas perdas eram avaliadas como toleráveis. Esse comportamento se assemelha ao 
que Chandler, DeTienne, McKelvie, e Mumford (2011) identificaram em seu estudo de validação: no effectuation, o empreendedor predetermina o quanto está disposto a perder e experimentar dentro dos limites dessa restrição.

Somente após a concretização da entrada da empresa no mercado e o levantamento do investimento que a empresa conseguiu recursos extras e pôde pagar pró-labores para seus fundadores e também contratar mais pessoas. Mesmo após ter recebido investimento, percebe-se a tendência de se utilizar sempre os recursos de menor custo em detrimentos de outros, ou seja, seguindo-se o princípio de perdas toleráveis, de minimização de perdas, e não de maximização do potencial de lucratividade. Dessa maneira, verifica-se o alinhamento dos achados desse estudo ao primeiro pilar do effectuation (Wiltbank et al., 2006; Sarasvathy, 2008; Dew et al., 2009).

\subsubsection{Alianças estratégicas versus análise competitiva}

O segundo princípio proposto por Sarasvathy (2001) sugere que o causation é baseado em análises competitivas, enquanto o effectuation, por outro lado, foca em parcerias estratégicas e no pré-comprometimento das partes interessadas visando a redução de incertezas.

A importância da rede de relacionamentos desenvolvida em experiências profissionais passadas evidenciou, em diversos momentos, a formação das alianças estratégicas: consultas a gestores de RH, headhunters, fundadores de empresas de sites de relacionamento, indicação de contatos estratégicos, indicação de profissionais específicos, entre outras.

Ao vislumbrar a possibilidade de resolver um problema apresentado pelo mercado, a preocupação inicial da empresa não foi a de entender como se diferenciaria de seus competidores, mas a de realizar alianças estratégicas com parceiros que se comprometessem com o negócio. Este ponto pode ser identificado na formação de sociedade com pessoas com formações (Administração, Engenharia e Publicidade) e experiências (RH, empreendedorismo, tecnologias digitais) complementares e na contratação de um estatístico experiente.

Com base no contato contínuo com clientes e na troca frequente de feedbacks sobre o produto, nota-se a preocupação da empresa em reduzir as incertezas através da melhoria/construção (e não previsão) da solução em conjunto com as partes interessadas. Nesse ponto, fica clara a abordagem e flexível (em contraposição à prescrição e à normatividade de Kotler e Porter) dos fundadores. Nos termos de Chandler et al. (2011) e Fisher (2012), os empreendedores respondiam às oportunidades não planejadas à medida que elas surgiam.

Outros exemplos da importância das parcerias para a empresa foram a escolha do local do escritório, fazendo uso de estrutura familiar; e em como ocorreu o processo de escolha dos investidores, baseada não somente no montante de capital que estavam dispostos a investir, mas também no conhecimento, experiência e relacionamentos em áreas que a empresa considerava estratégicas para o negócio.

\subsubsection{Exploração das contingências versus exploração de conhecimento pré-existente}

O causation foca na exploração de conhecimentos pré-existentes, como uma expertise em uma nova tecnologia em particular. O effectuation, por sua vez, considera as contingências como oportunidades de obter vantagem competitiva (Sarasvathy, 2001). 
Fica evidente no caso estudado que a empresa não foi baseada em um conhecimento pré-existente, e sim no interesse pessoal de sua fundadora. Apesar da experiência dos fundadores em áreas-chave (e.g., RH, tecnologia), não havia expertise como estatística e desenvolvimento de software.

A empresa surgiu a partir de uma vontade bastante vaga e foi evoluindo a partir da exploração de contingências. Como exemplo, estão: a descoberta de um problema no mercado por meio de conversas desestruturadas com empresas do setor; a inspiração encontrada no caso do eHarmony, empresa que atua em mercado totalmente diferente da IA-Recruta; a apresentação, por meio das alianças estratégicas, de um estatístico que teve papel fundamental na construção da primeira versão do produto; a necessidade de aprofundamento no estudo sobre cultura organizacional; e a redefinição do público-alvo após a aprovação em programa de aceleração voltado ao atendimento de grandes empresas.

Esses comportamentos são consistentes com outros casos encontrados na literatura (Fisher, 2012; Laine \& Galkina, 2017), especialmente quanto à experimentação (diferentes abordagens no mercado antes de se decidir por um conceito de negócio) e ao pré-compromisso (estabelecer relacionamentos iniciais com clientes, fornecedores e outros parceiros estratégicos para reduzir a incerteza e distribuir a responsabilidade para outras partes interessadas).

\subsubsection{Controle de um futuro imprevisível versus previsão de um futuro incerto}

Segundo Sarasvathy (2001), o causation foca em aspectos previsíveis de um futuro incerto. A lógica no uso desses processos é: "ao passo que se pode prever o futuro, pode-se controlá-lo". Já o effectuation foca em aspectos controláveis de um futuro imprevisível. A lógica por trás desses processos é: "ao passo que se pode controlar o futuro, não há a necessidade de prevê-lo".

É possível notar que os empreendedores estão sempre bastante próximos (em termos de relacionamento e também físicos) aos seus parceiros e clientes, fazendo experimentos constantes e codesenvolvendo as soluções. Dessa forma, no caso de um cliente reprovar determinado serviço/produto oferecido pela empresa, a atenção se volta rapidamente ao entendimento do motivo desse resultado. A proximidade dos clientes e parceiros é utilizada tanto como forma de minimizar as perdas toleráveis como para controlar um futuro tomado como imprevisível.

Não são realizadas previsões, e sim (re)ações rápidas frente aos problemas imprevisíveis, consoante com estudos empíricos da literatura (Chandler et al., 2011; Fisher, 2012; Laine \& Galkina, 2017).

Esse também é o motivo pelo qual os empreendedores não viam sentido em montar um plano de negócios nesse estágio de desenvolvimento em que havia ainda muitas incertezas sobre o negócio. Isso reforça a ideia de não buscar prever resultados futuros, mas sim construí-los (e controlá-los) aos poucos.

\subsubsection{Evidências da lógica effectuation}

A Tabela 5 relaciona diversos indicadores do effectuation às ações dos empreendedores no caso estudado: 
Tabela 5 - Evidências da lógica effectuation no caso estudado Indicadores da lógica effectuation

Exemplo de evidência observada no caso

Objetivos vagos no início

Fundadora explicitou que não havia clareza em relação ao objetivo

Influência dos fundadores (quem eu conheço, o que eu sei, e quem sou)

Escolha do setor por vontade pessoal da fundadora

Realização de poucas (ou nenhuma) pesquisas de mercado

Objetivos são atraentes porque são "factíveis" e não porque maximizam os lucros

As ideias surgem largamente por meio de experiências pessoais, ao invés de esforços deliberados de busca

Pré-comprometimento de parceiros como fator vital no desenvolvimento dos objetivos

Ao invés de buscar pelo "melhor" parceiro (e.g. maior investimento), busca-se parceiros comprometidos com o processo

Utilização de contingências como oportunidades

Realização de experimentações com versões beta e investimento mínimo

Escolha do produto a ser desenvolvido com base na possibilidade de realização e não no potencial de lucratividade (que nem mesmo foi calculado)

Utilização de redes neurais e do conceito de matching cultural a partir de experiências profissionais passadas com $\mathrm{RH}$ empreendedorismo e tecnologias digitais

Papel fundamental do profissional em estatístico no desenvolvimento da primeira versão do produto

Escolha dos investidores baseada em sua atuação em áreas que a empresa considerava estratégicas para o negócio, e não somente no montante de capital que estavam dispostos a investir

Redefinição do público-alvo após a aprovação em programa de aceleração voltado ao atendimento de grandes empresas

Fonte: Elaborado pelos autores.

A história dos empreendedores - suas experiências profissionais, seus conhecimentos e interesses pessoais - e suas redes de relacionamentos foram fundamentais para no processo de criação da empresa. Tal importância ficou evidente tanto na escolha do mercado em que a empresa atuaria (i.e., setor de $\mathrm{RH}$, devido ao interesse pessoal da fundadora), quanto no estabelecimento dos primeiros parceiros estratégicos (e.g., mentores, clientes, investidores) que, estando comprometidos, possibilitaram que a empresa avançasse de forma com que as incertezas fossem reduzidas (e.g., lançamento da versão beta do produto com investimento mínimo). Tal maneira de agir está de acordo com o effectuation, uma vez que, segundo Sarasvathy e Dew (2005), o empreendedor parte do controle dos recursos existentes (quem eu sou, quem eu conheço e o que eu conheço), para então buscar a obtenção do comprometimento dos stakeholders, realizar experimentações e, então, absorver as informações do mercado, incorporando-as no processo de criação da empresa - o que evidencia a dinamicidade e iteratividade que caracterizam o processo effectuation (Wiltbank et al., 2006).

As evidências observadas perpassam todos os pilares do effectuation (perdas toleráveis, alianças estratégicas, exploração das contingências e controle de um futuro imprevisível) e reforçam a importância dessa 
abordagem para o entendimento da ação empreendedora em situações de incerteza e a contribuição desse estudo à lacuna da literatura referente a estudos empíricos sobre effectuation (Sarasvathy, 2001; Tasic, 2007; Matalamäki, 2017).

\section{Considerações finais}

O estudo de Sarasvathy (2001) representou um marco para as pesquisas sobre ação empreendedora por confrontar e criticar de maneira contundente a lógica causal dominante desde os anos 1960 (e.g., Ansoff, 1965; Porter, 1979; Kotler, 1991). A pesquisa sobre o effectuation encontra-se na transição para um estágio de desenvolvimento maduro, o que requer a realização de mais casos empíricos que validem tal abordagem e contribuam para o avanço sobre o seu entendimento.

Esse artigo investigou o caso de uma startup pioneira no uso de inteligência artificial e matching cultural no processo de recrutamento e seleção para empresas, visando analisar o comportamento dos empreendedores sob a ótica do effectuation. O caso escolhido se mostrou adequado ao objetivo, pois está posicionado no quadrante suicida, isto é, casos que envolvem novos produtos e novos mercados e, por conseguinte, alta incerteza.

Constatou-se o alinhamento entre a ação empreendedora dos fundadores e os quatro pilares do effectuation (Sarasvathy, 2001, 2008; Wiltbank et al., 2006; Dew et al., 2009). Além disso, os achados desse trabalho são consistentes com estudos prévios que buscaram validar o construto do effectuation. Por exemplo, indicadores fundamentais como a experimentação, a flexibilidade e o pré-comprometimento (Chandler et al., 2011; Fisher, 2012; Laine \& Galkina, 2017) foram identificados. Assim, é possível concluir que há fortes evidências de que a lógica effectuation foi aplicada no processo de criação e desenvolvimento da IA-Recruta e, desse modo, o estudo atingiu seu objetivo ao servir como um caso de validação de tal conceito.

Embora tenham sido aplicados diversos instrumentos de pesquisa (entrevistas, observação direta e análise documental) de forma a permitir a triangulação dos dados, a realização de estudo de caso único permanece como limitação. Assim, como trabalho futuro, sugere-se o estudo da rede de effectuation, ideia já presente no modelo proposto por Sarasvathy e Dew (2005) e Wiltbank et al. (2006). Nesse sentido, o conceito de ecossistema de inovação tem atraído crescente interesse dos pesquisadores (Gomes, Facin, Salerno, \& Ikenami, 2018), especificamente em relação ao entendimento das ações dos empreendedores para lidar com incertezas coletivas, i.e., incertezas que envolvem um grupo de atores do ecossistema de inovação (Gomes, Salerno, Phaal, \& Probert, 2018).

Espera-se que esse artigo seja útil a todos os interessados no tema da ação empreendedora: pesquisadores, estimulando o avanço da pesquisa sobre effectuation, que se encontra na transição para um estágio de maturidade; empreendedores, de forma a possibilitar um maior entendimento sobre suas estratégias e comportamentos; e profissionais da área de empreendedorismo, sejam estes professores, que podem utilizar este caso como exemplo de validação do effectuation, ou investidores e demais atores do ecossistema de inovação, a partir do entendimento sobre como agem os empreendedores com os quais se relacionam. 
Referências

Ansoff, I. (1965). Corporate strategy: an analytic approach to business policy for growth and expansion. New York, NY: McGraw- Hill.

Bird, B., Schjoedt, L., \& Baum, J. R. (2012). Entrepreneurs' behavior: Elucidation and measurement. Entrepreneurship Theory and Practice, 36(5), 889-913.

Chandler, G.N., DeTienne, D., McKelvie, A., \& Mumford, A. (2011). Causation and effectuation processes: A validation study. Journal of Business Venturing, 26, 375-390.

De Meyer, A., Loch, C. H., \& Pich, M. T. (2002). Managing project uncertainty: from variation to chaos. MIT Sloan Management Review, 43(2), 60.

Dew, N., \& Sarasvathy, S. D. (2002). What effectuation is not: further development of an alternative to rational choice. Proceedings of the Annual Meeting of the Academy of Management, Denver, CO, USA, 62.

Dew, N., Read, S., Sarasvathy, S. D., \& Wiltbank, R. (2009). Effectual versus predictive logics in entrepreneurial decision-making: Differences between experts and novices. Journal of Business Venturing, 24(4), 287-309.

Dougherty, D. (2017). Taking advantage of emergence for complex innovation eco-systems. Journal of Open Innovation: Technology, Market, and Complexity, 3(1), 14.

Drucker, P. F. (1998). The discipline of innovation. Harvard Business Review, 76, 149-157.

Edmondson, A. C., \& McManus, S. E. (2007). Methodological fit in management field research. Academy of Management Review, 32(4), 1246-1264.

Fiet, J. O., \& Patel, P. C. (2006). Entrepreneurial discovery as constrained, systematic search. Small Business Economics, 30(3), 215-229.

Fisher, G. (2012). Effectuation, causation, and bricolage: a behavioral comparison of emerging theories in entrepreneurship research. Entrepreneurship Theory and Practice, 36(5), 1019-1051.

Gomes, L. A., Facin, A. L. F., Salerno, M. S., \& Ikenami, R. K. (2018). Unpacking the innovation ecosystem construct: Evolution, gaps and trends. Technological Forecasting and Social Change, 136, 30-48.

Gomes, L. A. B., Salerno, M. S., Phaal, R., \& Probert, D. R. (2018). How entrepreneurs manage collective uncertainties in innovation ecosystems. Technological Forecasting \& Social Change, 128, 164-185.

Kirzner, I. M. (1979). Perception, opportunity, and profit: studies in the theory of entrepreneurship. Chicago: University of Chicago Press.

Kotler, P. (1991). Marketing management. Englewood Cliffs: Prentice-Hall.

Laine, I., \& Galkina, T. (2017). The interplay of effectuation and causation in decision making: Russian SMEs under institutional uncertainty. International Entrepreneurship and Management Journal, 13(3), 905-941.

Langley, A. (1999). Strategies for theorizing from process data. Academy of Management Review, 24(4), 691-710.

Leifer, R., McDermott, C. M., O'Connor, G. C., Peters, L. S., Rice, M., \& Veryzer, R. W. (2000). Radical innovation: How mature companies can outsmart upstairs. Boston: Harvard Business School Press.

Matalamäki, M. J. (2017). Effectuation, an emerging theory of entrepreneurship-towards a mature stage of the development. Journal of Small Business and Enterprise Development, 24(4), 928-949.

March, J. (1978). Bounded rationality, ambiguity, and the engineering of choice. The Bell Journal of Economics, 9(2), 587-608.

Mintzberg, H. (1978). Patterns in strategy formation. Management Science, 14(9), 934-948.

Neck, H. M., \& Greene, P. G. (2011). Entrepreneurship education: known worlds and new frontiers. Journal of Small Business Management, 49(1), 55-70.

Perry, J. T., Chandler, G. N., \& Markova, G. (2012). Entrepreneurial effectuation: a review and suggestions for future research. Entrepreneurship Theory and Practice, 36(4), 837-861.

Porter, M. (1979). How Competitive Forces Shape Strategy. Harvard Business Review, 57(2), 137-145.

Rice, M. P., O’Connor, G. C., \& Pierantozzi, R. (2008). Implementing a learning plan to counter project uncertainty. MIT Sloan Management Review, 49(2), 54.

Salusse, M. A. Y., \& Andreassi, T. (2016). O Ensino de Empreendedorismo com Fundamento na Teoria Effectuation. Revista de Administração Contemporânea, 20(3), 305-327.

Sarasvathy, S. D. (2001). Causation and effectuation: Toward a theoretical shift from economic inevitability to entrepreneurial contingency. Academy of Management Review, 26(2), 243-263.

Sarasvathy, S. D. (2003). Entrepreneurship as a science of the artificial. Journal of Economic Psychology, 24(2), 203-220.

Sarasvathy, S. D. (2008). Effectuation: elements of entrepreneurial expertise. Massachussets: Edward Elgar Publishing, Inc. 
Sarasvathy, S. D., \& Dew, N. (2005). New market creation through transformation. Journal of Evolutionary Economics, 15(5), 533-565.

Sarasvathy, S.D. \& Kotha, S. (2001). Dealing with Knightian uncertainty in the new economy: The RealNetworks case. In J. Butler (Ed.). Research on Management and Entrepreneurship (pp. 31-62). Greenwich: IAP Inc.

Schumpeter, J. A. (2004). The theory of economic development. Cambridge: Harvard University Press.

Shane, S. (2012). Reflections on the 2010 AMR decade award: Delivering on the promise of entrepreneurship as a field of research. Academy of Management Review, 37(1), 10-20.

Shane, S., \& Venkataraman, S. (2000). The promise of entrepreneurship as a field of research. Academy of Management Review, 25(1), 217-226.

Simon, H. A. (1959). Theories of decision-making in economics and behavioral science. The American Economic Review, 49(3), 253-283.

Tasic, I. A. B. (2007). Estratégia e Empreendedorismo: decisão em criação sob incerteza. Dissertação de mestrado, Fundação Getúlio Vargas, São Paulo, SP, Brasil.

Tasic, I., \& Andreassi, T. (2008). Strategy and Entrepreneurship: Decision and Creation Under Uncertainty 1. Journal of Operations and Supply Chain Management, 1(1), 12-23.

Weick, K. (1979). The social psychology of organizing. Reading, MA: Addison-Wesley.

Wiltbank, R., Dew, N., Read, S., \& Sarasvathy, S. D. (2006). What to do next? The case for non-predictive strategy. Strategic Management Journal, 27(10), 981-998.

Yin, R. K. (2015). Estudo de Caso: Planejamento e Métodos. Porto Alegre: Bookman.

Recebido em: 30 maio 2018 / Aprovado em: 26 set. 2018

\section{Para referenciar este texto}

Barros, B. R., Sigahi, T. F. A. C., \& Saltorato, P. (2020). Confrontando a visão clássica da ação empreendedora: a lógica effectuation como forma de lidar com incertezas. Exacta, 18(2), 259-277. https://doi.org/10.5585/ExactaEP.v18n2.8738. 